\title{
PEDAGOGY
}

\section{СОВРЕМЕННЫЕ ОБРАЗОВАТЕЛЬНЫЕ ТЕХНОЛОГИИ КАК ЗАЛОГ МОДЕРНИЗАЦИИ ПРОЦЕССА ПРЕПОДАВАНИЯ ПРЕДМЕТА “ФИЗИЧЕСКАЯ КУЛЬТУРА"}

\author{
Артак Гарникович Степанян \\ Заведующий отделом магистратуры Государственного института физической культуры и \\ спорта Армении, к.п.н., дочент
}

DOI: https://doi.org/10.31435/rsglobal_ijitss/30112019/6819

\section{ARTICLE INFO}

Received 17 September 2019 Accepted 10 November 2019

Published 30 November 2019

\section{KEYWORDS}

physical education, school children, teacher, educational technology, teaching,

innovation.

\begin{abstract}
The article considers the peculiarities of modern educational technologies using at "Physical Training" lessons. The results of theoretical analysis and practical work show that the use of these technologies will make the teaching process more effective.

The use of didactic materials and creative approach to the teaching process will increase and enrich the content of the subject, improve the quality of the lessons and contribute to the involvement of schoolchildren in physical culture and sports.
\end{abstract}

Citation: Артак Гарникович Степанян. (2019) Sovremennye Obrazovatel'nye Tekhnologii kak Zalog Modernizacii Processa Prepodavaniya Predmeta "Fizicheskaya Kul'tura". International Journal of Innovative Technologies in Social Science. 8(20). doi: 10.31435/rsglobal_ijitss/30112019/6819

Copyright: (C) 2019 Артак Гарникович Степанян. This is an open-access article distributed under the terms of the Creative Commons Attribution License (CC BY). The use, distribution or reproduction in other forums is permitted, provided the original author(s) or licensor are credited and that the original publication in this journal is cited, in accordance with accepted academic practice. No use, distribution or reproduction is permitted which does not comply with these terms.

Модернизация национальной системы физического образования школьников требует коренных изменений процесса физического воспитания. Поэтому необходимо широкое внедрение современных образовательных технологий в процесс преподавания физической культуры.

В данном контексте следует отметить, что педагогическая деятельность физического воспитания предполагает комплексный подход к преподаванию физической культуры, так как данный процесс является важным и эффективным средством не только физического, но и умственного, нравственного, эстетического, духовного и социального развития [6].

В данном случае учитель физической культуры в процессе физического воспитания должен обращать особое внимание на формирование мотивации и требований к регулярным выполнениям физических упражнений, воспитание нравственных и волевых качеств, формирование навыков командной работы и коммуникативной культуры [10].

Учащихся необходимо знакомить со способами креативного применения освоенных знаний, умений и навыков для обеспечения высокого уровня физической и умственной работоспособности, укрепления здоровья и проведения самостоятельных тренировок.

Что касается ведущих тенденций современного урока физической культуры, то к ним мы относим высокую направленность на физкультурное образование, так как важнейшим фактором его является правильное формирование у школьников ценностей физической культуры [1].

Одним из основных требований к современному уроку физической культуры является так же дифференцированный и индивидуальный подход к учащимся с учетом состояния их 
здоровья, физического развития, половой принадлежности, двигательной подготовленности и психологических особенностей. Дифференцированный и индивидуальный подход очень важен в процессе физического воспитания школьников как с низкими, так и с высокими результатами. Индивидуальный подход заключается не в предъявлении одинаковых требований ко всем, он, как правило, основан на определении возможностей и наклонностей каждого ученика, его природных данных и уровня подготовленности. Данный подход дает возможность решать задачи физического воспитания в полном объеме.

Еще одной отличительной чертой современного урока физической культуры является вовлечение учеников в реализацию совместного учебного процесса с учителем. Совместное решение учащимися поставленных перед ними задач значительно стимулирует их познавательную деятельность [14].

Таким образом, процесс модернизации содержания учебного процесса физической культуры в общеобразовательной школе предполагает, что интенсивность данного процесса, которая должна проявляться в повышении целенаправленности учебного процесса, в конкретном осуществлении образовательной направленности, а следовательно в усилении мотивации к занятиям, в физическом самоусовершенствовании и в развитии необходимых навыков.

Конечно, сегодня только традиционные технологии не в состоянии полностью решить вышеизложенные задачи. Для этого современному учителю могут значительно помочь современные образовательные технологии. Поэтому, современный педагог должен владеть знаниями в данной области и уметь плодотворно использовать их в своей педагогической деятельности [2].

Учитель физической культуры, используя современные образовательные технологии в своей педагогической деятельности, сможет не только повысить уровень физической подготовленности учеников, но и развить их творческий потенциал, тем самым подготовить их к рабочей конкуренции в будущем.

Выбор образовательных технологий для уроков физического воспитания должен быть обусловлен такой организацией учебного процесса, которая обеспечит оптимизацию процесса физического воспитания. Этого можно добиться при педагогически обоснованном расчете затрачиваемого времени, правильном распределении физической нагрузки учеников и сокращении воспроизводимой информации.

Таким образом, внедрение и широкое применение современных образовательных технологий дает возможность продуктивно проводить классные и внеклассные занятия и добиться высоких показателей в учебном процессе [4, 12].

В течение продолжительного времени в учебном процессе апробировались разработанные нами ряд образовательных технологий физического воспитания школьников (рис. 1), которые получили положительную оценку специалистов, их характеристика приводится ниже.

Дифференцированные технологии физического воспитания (ДТФВ).

ДТФВ являются важнейшей составляющей процесса модернизации физического воспитание. Они представляют собой всестороннее физическое воспитание учащихся, предусматривают дифференцированное педагогическое обучение, формирование соответствующих знаний, двигательных умений и навыков, воспитание двигательных способностей.

Дифференцированное обучение двигательным действиям. Дифференцированное обучение двигательным действиям или дифференцированное решение каких-либо двигательных задач предполагает возможность выбора различных способов. В этом случае каждый ученик может освоить физическое упражнение предпочтительными для себя действиями, что послужит основой для формирования его индивидуального стиля.

Дифференщированное воспитание двигательных способностей. Дифференцированное воспитание двигательных способностей в группах учащихся с разным уровнем подготовленности необходимо осуществлять с применением как однотипных, так и разных средств и методов, однако, планируемая нагрузка должна быть неадекватной. $\mathrm{B}$ результате, уровень физической подготовленности учеников существенно улучшается. В наиболее слабых группах ученики быстро заканчивают выполнение упражнений, следовательно времени на отдых и восстановление остается больше. Для учеников с недостаточным уровнем физической подготовленности предлагается применять карты с индивидуальными заданиями, в которых указаны виды упражнений, последовательность их выполнения, количество повторений, темп выполнения [11]. 
СОВРЕМЕННЫЕ ОБРАЗОВАТЕЛЬНЫЕ ТЕХНОЛОГИИ ФИЗИЧЕСКОГО ВОСПИТАНИЯ ШКОЛЬНИКОВ

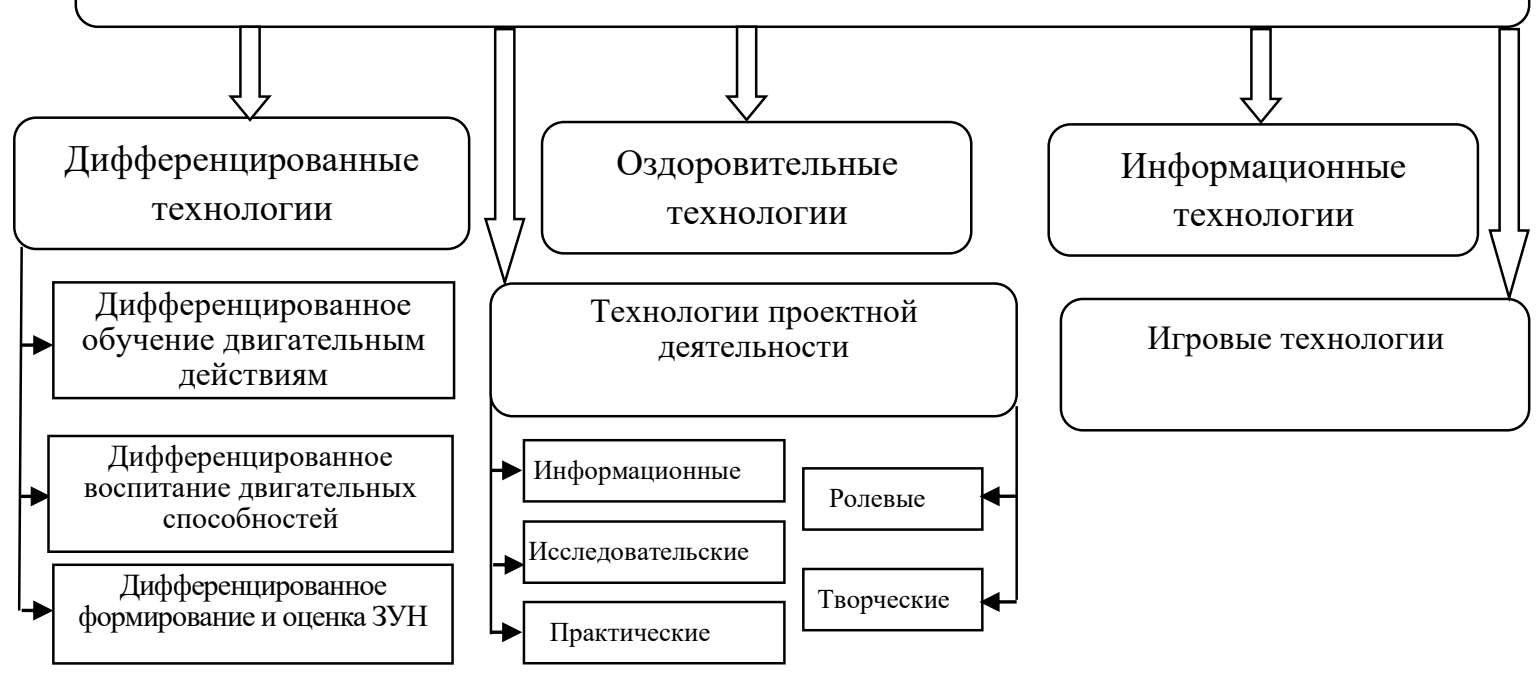

Рис. 1. Современные образовательные технологии, применяемые на уроках физического воспитания. Формирование необходимых знаний и методических умений у школьников. Дифференцированная технология формирования знаний и методических навыков предполагает:

- определение уровня образованности школьников с помощью диагностических тестов (это является основой для распределения учащихся по группам разной степени подготовленности),

- разделение задач изучаемой темы согласно уровню образованности и подготовленности учеников,

- распределение теоретического материала программы. Учащимся предлагаются разные по содержанию, объему и сложности задания. Они могут быть в виде лекционных материалов, статей, докладов, рефератов, проектной деятельности, составления комплексов общеразвивающих упражнений и т. д.

В процессе практических занятий ученикам следует объяснять влияние упражнений на организм. Особое внимание нужно уделять технике упражнений и правилам соблюдения техники безопасности. Необходимо провести педагогический разбор урока, обращая внимание на ошибки и недоработки.

Дифференцированная оченка физической и технической подготовленности учащихся. При оценивании учащихся необходимо учитывать не только уровень их физической подготовленности, но и степень владения умениями и навыками выполнения физических упражнений, соблюдение правил здорового образа жизни, уровень теоретических знаний, трудолюбие, умение осуществлять физкультурно-оздоровительную деятельность. Необходимо поощрять и воодушевлять занимающихся, внушать уверенность в собственных возможностях. В отдельных случаях необходимо сдерживать излишнее воодушевление. Все это формирует положительное отношение учащихся к выполнению заданий, создает предпосылки для общественно активной жизни. Физическую подготовленность школьников нецелесообразно оценивать только по результатам выполнения конкретных нормативов, но по динамике и сдвигам индивидуальных результатов.

Дети, временно освобожденные от уроков и вовлеченные в специальную группу по состоянию здоровья, также участвуют в занятиях - помогают в подготовке спортивного инвентаря, судейству, а также знакомятся с теоретическим материалом и техникой выполнения двигательных действий. С детьми, специальной медицинской группы, занятия обычно проводятся во внеурочное время по программе, рекомендованной специалистом. Данная работа также подлежит оцениванию.

Всестороннее исследование работ, проводимых со школьниками, сопоставление разных данных дает возможность выявить причины отставания детей, определить главную причину и оказать педагогическое воздействие на основе дифференцированной методики преподавания. 


\section{Информационные технологии.}

Одним из основных требований модернизации учебного процесса в учебных заведениях является применение информационных технологий, что способствует повышению эффективности урока. Современное образование должно не только обеспечивать привитие учащимся определенных знаний, но и формировать у них умение самостоятельно приобретать эти знания. Усвоение и обобщение полученных знаний становятся не только целью умственного развития занимающихся, но и способствующим этому развитию средством [5]. Применение компьютерных технологий в учебном процессе дает обучаемым возможность не просто механически усваивать полученный материал, но и приобретать умения самостоятельного получения необходимых знаний.

На данном этапе традиционная модель преподавания предмета “Физическая культура" в общеобразовательных школах не всегда соответствует требованиям системы современного образования. Результаты практических изысканий автора [3] и обобщение многочисленных литературных источников дают возможность определить следующие пути применения информационных технологий в процессе педагогической деятельности учителя физической культуры:

- в процессе обучения основам предмета и подготовки к экзаменам,

- в процессе распределения нагрузки с учетом индивидуальных особенностей,

- при проведении самостоятельной работы по сбору информации,

- в процессе проведения внеклассных занятий в виде спортивных викторин, различных конкурсов и т.п,

- в процессе разработки проектов по развитию творческих и интеллектуальных способностей школьников, а также навыков самовыражения и совместной работы,

- во время работы с детьми с ограниченными физическими возможностями,

- при обучении учеников пользоваться интернетом для выполнения домашнего задания,

- при организации коммуникативных работ с целью привития навыков общения,

- в процессе подготовки рабочих программ, инструкций, дидактических материалов, тестовых заданий, различных докладов и методических работ.

Активными способами обучения, с использованием компьютерных технологий, являются мультимедийные презентации, выполненные с помощью компьютерной программы Power Point. Этот тип современной коммуникации включает в себя цифровые изображения, тексты разных форматов, картинки, анимации, а также аудио и видео изображения, которые дают возможность по-новому использовать текстовую, графическую, аудио-видео информацию, что способствует повышению продуктивности учебного процесса. Презентации обеспечивают интересную подачу информации большего объема за короткое время. Примечательно также, что они могут быть использованы в процессе всех видов занятий, таких как объяснение нового материала, практические и лабораторные работы, а также при оценке знаний обучающихся. В процессе объяснения нового материала такие презентации могут стать незаменимыми, т.к. ключевые части материала в определенном количестве представляются на слайдах, а учитель дополняет и разъясняет наиболее трудные моменты. Использование данной программы при оценивании знаний значительно сокращает потраченное не это время и способствует повышению объективности. Таким образом, можно заключить, что внедрение и целесообразное применение подобных технологий на уроках физической культуры дают возможность учителю представлять изучаемый материал более доступно, а ученикам помогают легче усваивать данную информацию в соответствии с их индивидуальными особенностями.

\section{Оздоровительные технологии.}

Усовершенствование образовательной парадигмы приводит к изменению статуса физической культуры как гуманитарного учебного предмета. Этим обусловлена как актуализация содержания физического образования, так и существенное изменение позиции учителя физической культуры, взгляда на его профессиональные и личностные качества, что приводит к переосмыслению и перестройке сущности его профессиональной деятельности [7]. Следовательно, личность учителя играет важнейшую роль в процессе актуализации физкультурного образования, т.к. его профессионализм и компетентность необходимое условие обеспечения необходимых результатов. Именно учитель несет ответственность за актуализацию физкультурного образования и должен создавать способствующие продуктивности условия учебного процесса. 
Учитель физической культуры несет также ответственность за здоровье учеников, их физическое, психическое, моральное и социальное развитие. Поэтому особое значение на уроках физической культуры следует придавать оздоровительным технологиям, которые представляют собой целостный комплекс, включающий в себя средства обучения физическим упражнениям и методам организации деятельности учеников. Целью оздоровительных технологий является обеспечение сохранения состояния здоровья учеников, формирование у них знаний, умений и навыков в области обеспечения здорового образа жизни, а также обучение правильному использованию приобретенных знаний в каждодневной жизни [13]. Именно в основе оздоровительных технологий лежит строгий учет возрастных и гендерных особенностей, оптимальное распределение и нормирование нагрузки и отдыха.

В то же время оздоровительные технологии в педагогической деятельности учителя физической культуры должны включать в себя следующее:

- четкое знание результатов медосмотра учеников и их строгий учет в процессе учебно-воспитательной работы,

- учет возрастных и гендерных особенностей, состояния здоровья ученика, уровень его развития и подготовленности в процессе обучения,

- тесное сотрудничество с родителями ученика с целью обеспечения здорового образа жизни в семье,

- создание условий, способствующих повышению у учащихся интереса к предмету,

- обеспечение здоровой морально-психологической обстановки на уроке,

- создание благоприятных условий для каждого ученика,

- обеспечение необходимых условий согласно санитарно-гигиеническим нормам (освещение, проветривание, режим терморегуляции).

\section{Технология проектной деятельности.}

Сущность данной технологии заключается в организации исследовательской деятельности. В прошлом было возможно относительно неплохо жить, опираясь на апробированные правила, повторяя уже принесшую успех деятельность, опираясь на опыт и знания предыдущих поколений, необходимо было только усвоить суть и форму применения данных норм [8]. Сегодня положение вещей в корне изменилось. Будущему гражданину недостаточны только теоретические знания. Бурное развитие науки приводит к тому, что теоретические знания становятся не актуальными. Конкурентоспособность на рынке труда зависит от активности человека, гибкости его мышления и его умения совершенствовать свои знания и опыт. Основой социального успеха является способность легко адаптироваться в постоянно меняющемся мире. И этому должна учить школа [11].

Применение данной технологии приводит к тому, что роль учителя физической культуры меняется, он перестает быть единственным источником знаний. Учитель только подсказывает ученикам пути изыскания необходимой информации и опыта. Применение проектной технологии дает возможность вовлекать учеников в самостоятельную когнитивную деятельность. Проект дает ученику возможность наиболее ярко проявить творческие способности. Это такой вид деятельности, который позволяет проявляться как индивидуально, так и в группе, испытать свои силы, вложить свои знания и показать полученные результаты. В частности, в процессе физического воспитания данный проект представляет собой развитие познавательного интереса учащихся к физической культуре и спорту, а расширение их кругозора способствует развитию творческих умений, формированию межпредметных связей, в частности, с такими предметами как математика, физика, информатика, химия, биология, история, [9].

Ученики применяют свои навыки владения компьютерными технологиями и знания, полученные на уроках по различным предметам, для подготовки проектных работ, рефератов и презентаций. Участник проекта собирает информацию по лично составленному плану, что дает возможность рассмотреть или оценить тот или иной процесс с различных точек зрения. Во время подготовки к защите проекта ученики старших классов изучают соответствующий материал, проводят опрос и презентации, издают газеты, буклеты, информационные листки.

Чрезвычайно важно, чтобы учащиеся понимали смысл и значение выполняемых упражнений и таким образом усваивали способы выполнения различных физических упражнений. Именно в этом и заключается путь к самостоятельности и самосовершенствованию. Необходимо не 
только развивать те или иные навыки школьников, но и научить их самостоятельному обучению. Этому будет способствовать только совместная деятельность учителя и ученика.

Следует отметить, что проекты бывают: творческие, информационные, ролевые, исследовательские, практические и т. д.

Творческие проекты обычно должны заканчиваться спортивными мероприятиями, например представление Олимпийских игр. В процессе подготовки информационных проектов учащиеся, согласно предлагаемой теме, пользуются данными из интернета и различными литературными источниками, а уже готовые материалы в виде чертежей, таблиц или буклетов помещают в специальном уголке спортивного зала или на сайте школы. В процессе подготовки ролевых проектов у учеников развиваются коммуникативные умения. В таких случаях авторы проекта устанавливают обратную связь с аудиторией.

Исследовательские проекты могут быть осуществлены во время различных экскурсий, походов и спортивных мероприятий, а их результаты могут быть представлены учебными фильмами или компьютерными презентациями.

Практический проект направлен на закрепление уже приобретенных умений и навыков. Учитель физической культуры поручает каждой группе учащихся составить конспект разных частей урока: вводная, основная часть и заключительная. На следующем уроке в присутствии учителя они самостоятельно организовывают и проводят урок, предварительно согласовав с учителем содержание его конспекта. Таким образом, в процессе данного проекта ученики представлены как личности, которые могут самостоятельно составить комплекс физических упражнений для воспитания различных двигательных способностей.

Использование данных технологий делает учебный процесс более целостным, интересным и насыщенным.

\section{Игровые технологии.}

Игровые технологии занимают важное место на уроках по различным учебным дисциплинам, т.к. игровая деятельность сама по себе является особенной областью образовательной деятельности. При использовании игровых технологий необходимо учитывать психо-педагогический тип ребенка, его возрастные и половые особенности, требования и интересы. Использование игровых технологий в процессе физического воспитания школьников приводит к повышению интереса учеников к предмету “Физическая культура”, способствует их сплочению, развивает стремление к конкурентности, прививает чувство ответственности и находчивость, а также мотивирует к достижению лучших результатов.

Игровые технологии на уроках физической культуры выполняют ряд функций, которые в дополненном виде обозначены на рисунке 2.

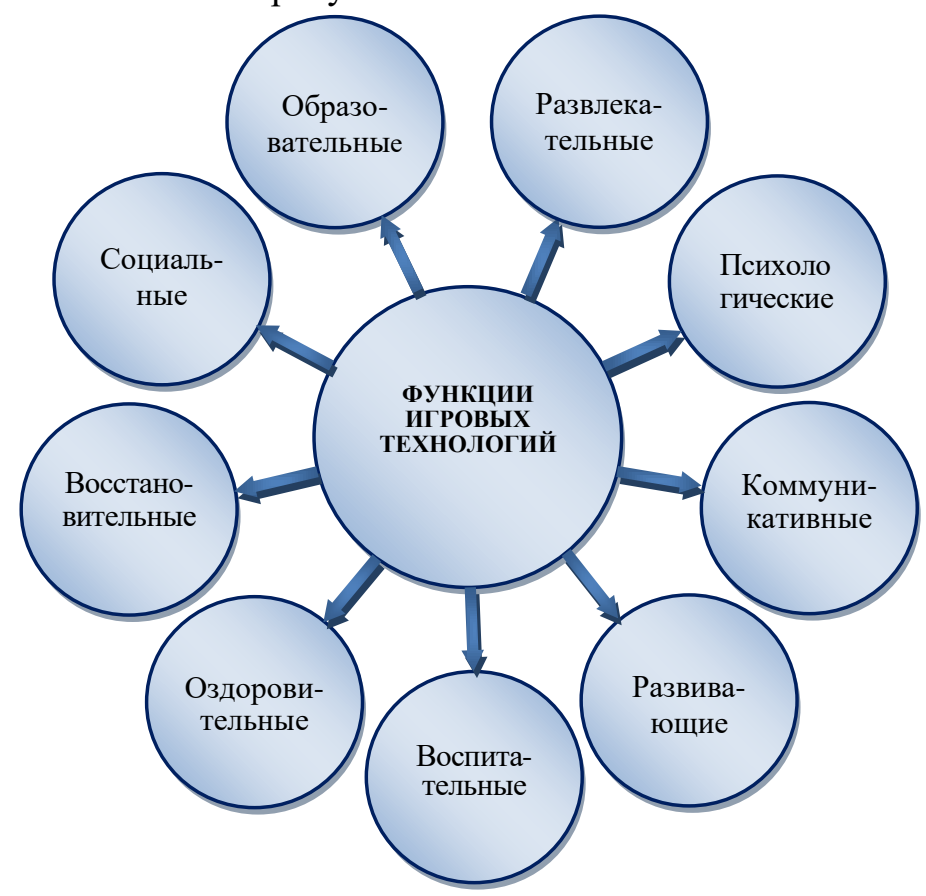

Рис. 2. Функции игровых технологий на уроках физической культуры 
Потенциал учащихся во время командных игр, таких как волейбол, баскетбол, гандбол, футбол и другие, возрастает в несколько раз по сравнению с теми занятиями, которые направлены только на выполнение отдельных упражнений. Таким образом, применение игровых технологий способствует более продуктивному и целенаправленному вовлечению учащихся в процесс физического воспитания.

Эти технологии дают возможность обеспечить эффективное и гармоничное развитие умственной, физической и эмоциональной нагрузки человека, а также зарядить положительными эмоциями, повысить настроение и доставить радость от процесса преодоления трудностей. Игровые технологии способствуют восстановлению физических и духовных сил, рождают дух здоровой спортивной борьбы и являются источником вдохновения.

Выводы. Таким образом, в итоге исследования автора и существующих в литературе образовательных технологий можно отметить их эффективность и непременную целесообразность использования в системе физического воспитания в учебных заведениях разного профиля.

\section{ЛИТЕРАТУРА}

1. Казарян Ф.Г., Степанян А.Г. Некоторые особенности современного урока физической культуры // Педагогическая мысль N 1-2, Ереван, 2010, стр. 65-69 (на армянском языке).

2. Степанян А.Г., Габриелян Г.Г. Инновационные подходы к содержанию и структуре предмета “Физическая культура" в общеобразовательной школе //Педагогика, 2011/II, стр. 12-21 (на армянском языке).

3. Степанян А.Г., Информационные технологии в процессе актуализации физического образования школьников //Педагогическая мысль N1-2, Ереван, 2012, стр. 77-82 (на армянском языке).

4. Петросян Г.А., Компетентный подход и обеспечение качества профессионального образования. Монография. Ереван, 2013, 264 стр (на армянском языке).

5. Белкин А.С., Нестеров В.В. Педагогическая компетентность: учебное пособие.-Екатеринбург: Учебная книга, 2003.-188 c.

6. Бим И.Л. Модернизация структуры и содержания школьного языкового образования// Иностранные языки в школе.-N 8.- 2005.- с. 2-5.

7. Иванов Д.А. О ключевых компетенциях и компетентностном подходе в образовании //Школьные технологии. Научнопрактический журнал. №5, 2007.- с. 51-62

8. Селевко Г.К. Современные образовательные технологии.-Учебное пособие. М.: Народное образование, 1998. $256 \mathrm{c}$.

9. Сластенин В.А. Педагогика: учеб. пособие для вузов /В.А. Сластенин, И.Ф. Исаев, Е.Н. Шиянов; ред. В.А. Сластенин.-3-е изд.- М.: Академия, 2004.- 576 с.

10. Хазова С.А.Развитие конкурентноспособности специалистов по физической культуре и спорту в процессе профессиональной подготовки: Монография. - Майкоп, 2011. - 371с.

11. Шерин В.С. Модель формирования компетентности управленческой деятельности специалиста по физической культуре и спорту //Педагогика и психология.- 2011. - № 5. - с. 147-150.

12. Шилько В.Г. Модернизация системы физического воспитания студентов на основе личностноориентированного содержания физкультурно-спортивной деятельности: автореф. дисс. д-ра пед. наук.- М., 2003. 47 c.

13. http://открытыйурок.рф/статьи/614838/.

14. https://nsportal.ru/shkola/fizkultura-i-sport/library/2017/04/01/statya-uchitel-fizicheskoy-kultury-i-ucheniк. 